\title{
Effect of Swirl Motion on Mixing Time in Water Bath Agitated by Upward Gas Injection
}

\author{
Yusuke TAKATSUKA and Manabu IGUCHI ${ }^{11}$ \\ Graduate Student, Graduate School of Engineering, Hokkaido University, North 13, West 8, Kita-ku, Sapporo $060-8628$ Japan. \\ 1) Division of Materials Science and Engineering, Graduate School of Engineering, Hokkaido University, North 13, West 8 , \\ Kita-ku, Sapporo 060-8628 Japan.
}

(Received on August 28, 2000; accepted in final form on November 9, 2000)

\begin{abstract}
Mixing time in a cylindrical water bath agitated by upward gas injection through a single-hole bottom nozzle and a J-shaped top lance was experimentally investigated in the presence of swirl motion of the bath. This gas injection process is regarded as one of models for steel refining processes. Measured values of the mixing time could not be predicted by empirical equations derived previously in the absence of the swirl motion. The effect of the swirl motion on the mixing time was significant, i.e., the mixing time was highly shortened in the presence of the swirl motion. An empirical equation was newly proposed for the mixing time as a function of the injection distance from the nozzle tip to the bath surface, gas flow rate, bath diameter, bath depth, and kinematic viscosity of liquid.
\end{abstract}

KEY WORDS: steelmaking; gas injection; mixing time; swirl motion; top lance; bubbling jet; bottom blowing; electrical conductivity.

\section{Introduction}

When gas is injected into a bath through a single-hole nozzle placed on the bottom center of a cylindrical vessel containing the bath, a vertical bubbling jet is generated in the bath. The bubbling jet does not always rise straight upwards. Under a certain blowing condition, it rises swirling around the vessel axis. ${ }^{1-3)}$ Swirl motion of liquid is also induced, being in phase with the swirl motion of the bubbling jet. This type of swirl motion of liquid appears for an aspect ratio, $H_{\mathrm{L}} / D$, ranging from approximately 0.3 to 1.0 and is very similar to the well-known rotary sloshing observed for a bath contained in a cylindrical vessel oscillating in the horizontal or vertical direction. The period of the swirl motion of liquid is almost the same as that of the rotary sloshing, while the amplitude becomes large with an increase in the gas flow rate.

Liquid contained in a cylindrical vessel is violently agitated in the presence of the swirl motion. At the same time spitting, splashing, and slopping are caused by the swirl motion. According to these disadvantages, the swirl motion has not been used practically in the steelmaking industries. From a different point of view, the swirl motion would bring about powerful mixing in the bath. In fact, one of the present authors applied the swirl motion to a snow melting process. A very high melting rate was expectedly realized in the presence of the swirl motion. ${ }^{4}$

If the spitting, splashing and slopping can be avoided, for example, by shielding the upper part of a bath, a novel refining process with high mixing efficiency would be devel- oped. However, there exists no information on the mixing time in the presence of the swirl motion. ${ }^{5-16)}$ Considering these circumstances, we carried out water model experiments and proposed an empirical equation for the mixing time in a water bath accompanied by the swirl motion.

\section{Experimental Apparatus and Procedure}

Figure 1 shows a schematic of the experimental apparatus. Three cylindrical vessels of different sizes were used. The inner diameter $D$ and the height $H$ of the vessels were $0.125 \mathrm{~m} \times 0.400 \mathrm{~m}, 0.200 \mathrm{~m} \times 0.400 \mathrm{~m}$, and $0.400 \mathrm{~m} \times 0.800$ m. Deionized water was filled to a prescribed depth, $H_{\mathrm{L}}$, in each vessel. Air was supplied with a compressor, and the air flow rate, $Q_{\mathrm{g}}$, was adjusted with a regulator and a mass flow controller from $40 \times 10^{-6} \mathrm{~m}^{3} / \mathrm{s}$ to $800 \times 10^{-6} \mathrm{~m}^{3} / \mathrm{s}$. The

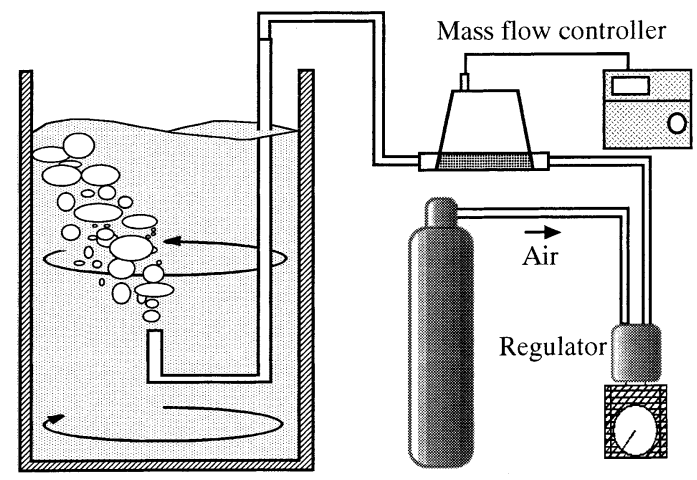

Fig. 1. Experimental apparatus. 


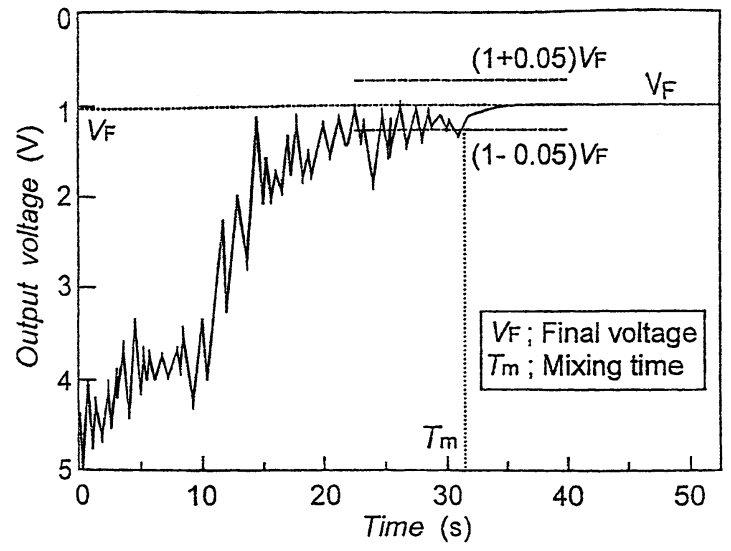

Fig. 2. Definition of mixing time.

air was injected into the bath through a bottom nozzle of an inner diameter of $2 \mathrm{~mm}$ and a J-shaped top lance of the same inner diameter. It is already known that the inner diameter of a bottom nozzle has a negligibly small effect on the mixing time. ${ }^{5,6)}$ A critical condition for the appearance of the swirl motion is given elsewhere. ${ }^{1)}$

Mixing time was determined on the basis of the history of the electrical conductivity of liquid in a bath. A dilute aqueous $\mathrm{KCl}$ solution was used as tracer. It was charged from the top of the bath onto the bath surface. The electrical conductivity was measured with an electrical conductivity sensor having a time constant of $0.25 \mathrm{~s}$. The output voltage approaches a constant value, $V_{\mathrm{F}}$, as time elapses. The mixing time is defined as the period from a moment of tracer charge to the moment at which the electrical conductivity finally crosses $0.95 V_{\mathrm{F}}$ or $1.05 V_{\mathrm{F}}$, as shown in Fig. 2. Details of the measurement method of the mixing time are given elsewhere. ${ }^{13)}$

\section{Experimental Results and Discussion}

\subsection{Bottom Gas Injection}

Measured values of mixing time for different three vessels are shown against gas flow rate in Figs. 3, 4 and 5, respectively. Each straight line in the figures was drawn so as to best fit the measured values for the same aspect ratio. The mixing time decreases with an increase in the gas flow rate, but increases with an increase in the bath diameter. One of the authors previously proposed the following empirical equation for the mixing time in a bottom blown bath in the absence of the swirl motion. ${ }^{13)}$

$$
T_{\mathrm{mB}}=1200 Q_{\mathrm{g}}^{-0.47} D^{1.97} H_{\mathrm{L}}^{-1} v_{\mathrm{L}}^{0.47}
$$

where $v_{\mathrm{L}}$ is the kinematic viscosity of liquid and the subscript $\mathrm{B}$ denotes bottom blowing.

Equation (1) is rewritten in a dimensionless form as follow:

$$
\begin{aligned}
& T_{\mathrm{mB}}\left(H_{\mathrm{L}} / D\right)(g / D)^{1 / 2}=4.21 \times 10^{3} \mathrm{Re}^{-0.47} \\
& \operatorname{Re}=D v_{\mathrm{sp}} / v_{\mathrm{L}} \\
& v_{\mathrm{sp}}=4 Q_{\mathrm{g}} /\left(\pi D^{2}\right) \text {. }
\end{aligned}
$$

being valid for

$$
30<\operatorname{Re}<3000
$$

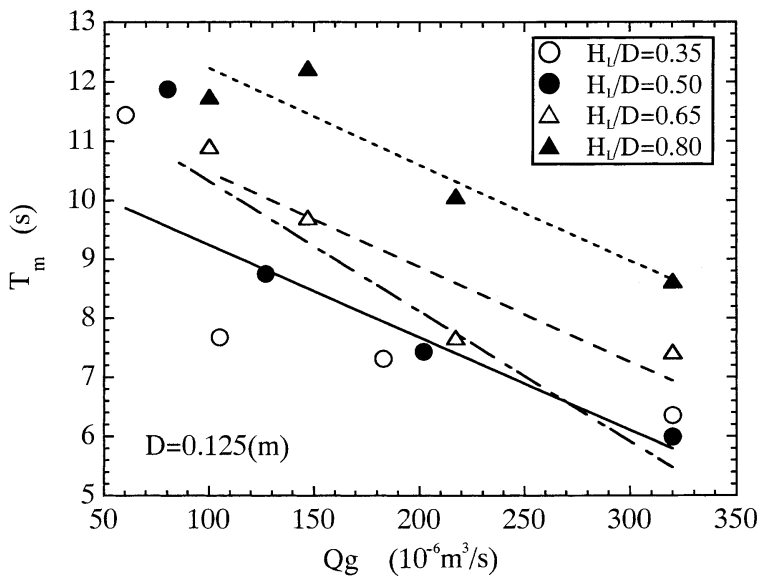

Fig. 3. Relationship between mixing time $T_{\mathrm{m}}$ and gas flow rate for $D=0.125 \mathrm{~m}$.

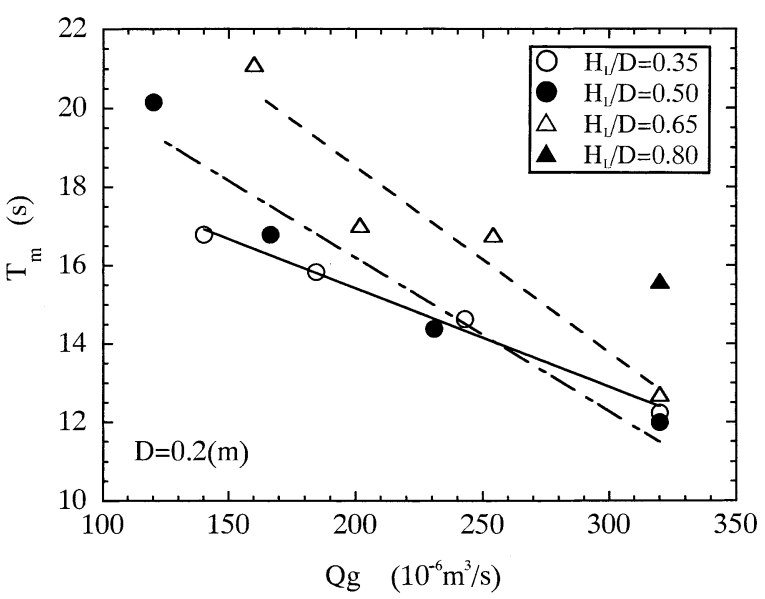

Fig. 4. Relationship between mixing time $T_{\mathrm{m}}$ and gas flow rate for $D=0.200 \mathrm{~m}$.

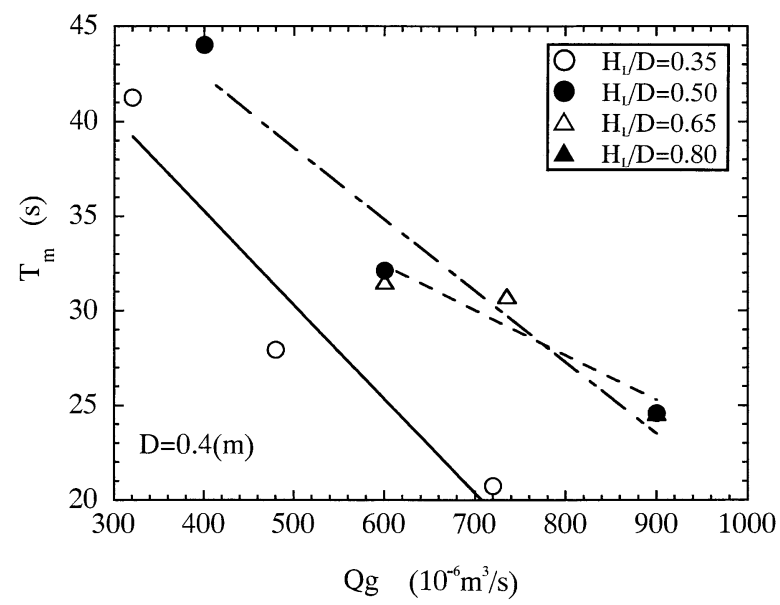

Fig. 5. Relationship between mixing time $T_{\mathrm{m}}$ and gas flow rate for $D=0.400 \mathrm{~m}$.

where $g$ is the acceleration due to gravity and $\mathrm{Re}$ is the Reynolds number based on the superficial velocity of gas, $v_{\text {sp. }}$.

Equation (1) is chosen here to correlate the measured values of mixing time in the presence of the swirl motion. All the mixing time values obtained in the present study are divided by Eq. (1) and replotted against the aspect ratio $H_{\mathrm{L}} / D$ in Fig. 6. The existing range of the swirl motion with 


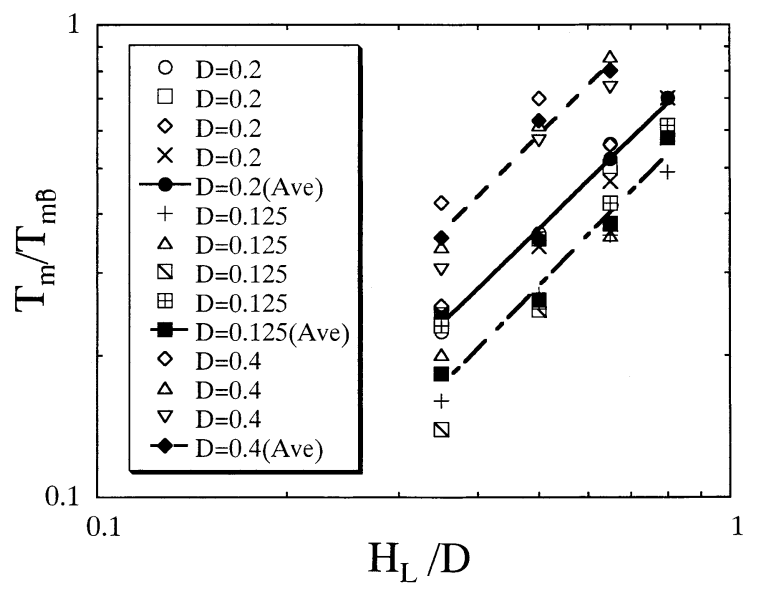

Fig. 6. Relationship between nondimensionalized mixing time and aspect ratio.

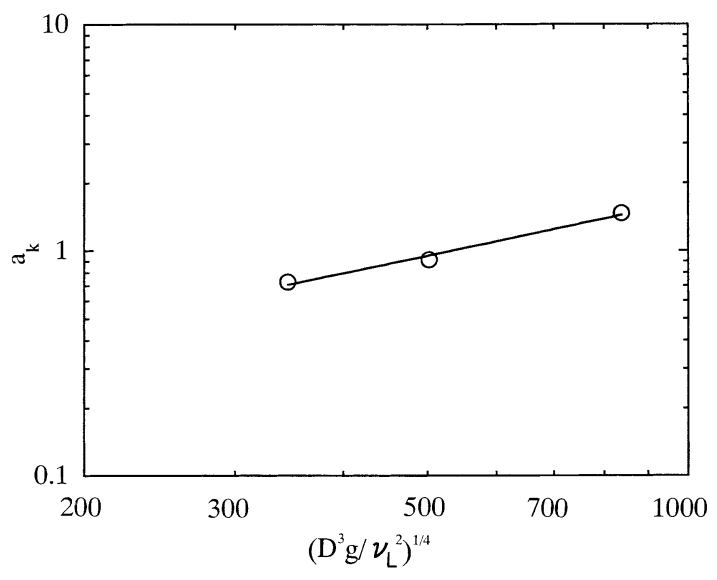

Fig. 7. Coefficient $a_{\mathrm{k}}$ as a function of $\left(D^{3} g / v_{\mathrm{L}}{ }^{2}\right){ }^{1 / 4}$

respect to the aspect ratio should be referred to the previous paper $^{1)}$. For every vessel a straight line was drawn through the mean of the measured values as close as possible. The gradient of every straight line is $4 / 3$, implying that the mixing time is proportional to $\left(H_{\mathrm{L}} / D\right)^{4 / 3}$. We therefore assume the following equation.

$$
T_{\mathrm{m}}=a_{\mathrm{k}}\left(H_{\mathrm{L}} / D\right)^{4 / 3} T_{\mathrm{mB}}
$$

Inspection of Fig. 6 suggests that the coefficient $a_{\mathrm{k}}$ is a function of the vessel diameter $D$.

Referring to Stokes's first problem, ${ }^{17)}$ we introduce the following representative length in order to nondimensionalize the vessel diameter $D$.

$$
\begin{gathered}
L=\left(v_{\mathrm{L}} T_{\mathrm{s}}\right)^{1 / 2} . \\
T_{\mathrm{s}}=k(D / g)^{1 / 2}
\end{gathered}
$$

where $T_{\mathrm{s}}$ is the period of the swirl motion and $k$ is a constant. It is known that $k$ is approximately $0.27 .{ }^{1)}$ The representative length $L$ denotes the distance for the radial momentum exchange between the bubbling jet and the surrounding liquid during a swirl period.

For convenience, $k$ is assumed to be unity and Eq. (8) is substituted into Eq. (7) to give

$$
L=\left(v_{\mathrm{L}}^{2} D / g\right)^{1 / 4}
$$

We can read $a_{\mathrm{k}}$ values from Fig. 6 . The $a_{\mathrm{k}}$ values thus ob-

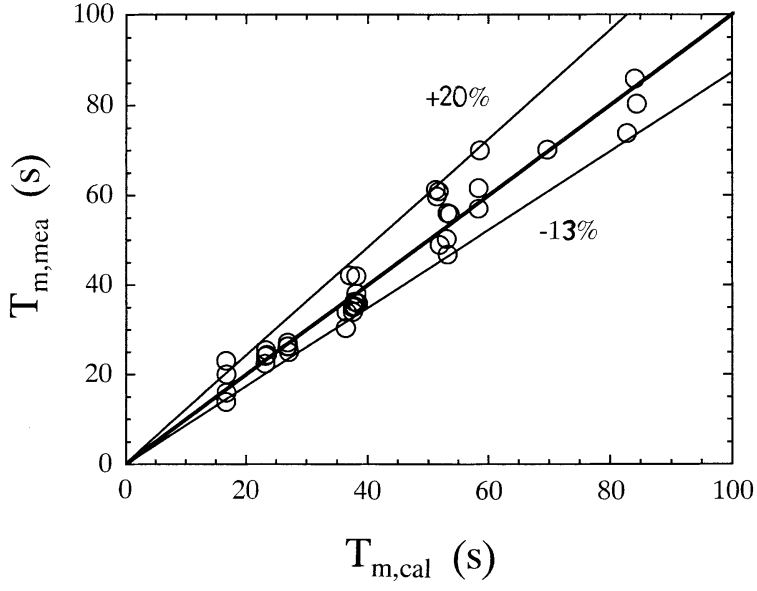

Fig. 8. Comparison of measured mixing time values with Eq. (12).

tained are plotted against $D / L$ in Fig. 7, where $D / L$ is expressed by

$$
D / L=\left(D^{3} g / v_{\mathrm{L}}^{2}\right)^{1 / 4}
$$

The measured values of $a_{\mathrm{k}}$ are approximated by

$$
a_{\mathrm{k}}=4.1 \times 10^{-3}\left(D^{3} g / v_{\mathrm{L}}^{2}\right)^{7 / 32} \quad\left(300<\left(D^{3} g / v_{\mathrm{L}}^{2}\right)^{1 / 4}<900\right)
$$

Combination of Eqs. (1), (6) and (11) yields.

$$
T_{\mathrm{m}}=4.92\left(D^{3} g / v_{\mathrm{L}}^{2}\right)^{7 / 32}\left(H_{\mathrm{L}} / D\right)^{4 / 3} Q_{\mathrm{g}}^{-0.47} D^{1.97} H_{\mathrm{L}}^{-1} v_{\mathrm{L}}^{0.47}
$$

All the mixing time values obtained in the presence of the swirl motion are compared with Eq. (12) in Fig. 8. It is evident that Eq. (12) can approximate the measured values within a scatter of $-13 \%$ to $+20 \%$.

Equation (12) can be rewritten by

$$
T_{\mathrm{m}}=4.92 g^{0.22} Q_{\mathrm{g}}^{-0.47} D^{1.27} H_{\mathrm{L}}^{0.33}{v_{\mathrm{L}}}^{0.03}
$$

The contribution of the kinematic viscosity of liquid, $v_{\mathrm{L}}$, was found to be very small and negligible. This fact implies that the bath accompanied by swirl motion of a bubbling jet is primarily mixed by strong wave motion caused by the swirl motion because the wave motion is not affected by the kinematic viscosity of liquid.

\subsection{Results for J-shaped Top Lance Gas Injection}

According to a previous study, ${ }^{18)}$ mixing time in a bath agitated by gas injection through a J-shaped top lance in the absence of the swirl motion can be given by the following empirical equation.

$$
T_{\mathrm{mJ}}=1200 Q_{\mathrm{g}}{ }^{-0.47} D^{1.97} H_{\mathrm{L}}{ }^{-1}{v_{\mathrm{L}}}^{0.47}\left(H_{\mathrm{in}} / H_{\mathrm{L}}\right)^{0.7-1.34 H_{\mathrm{L}} / D}
$$

where $H_{\text {in }}$ is the distance from the nozzle tip to the bath surface and the subscript $\mathrm{J}$ denotes the $\mathrm{J}$-shaped top lance. Referring to Eqs. (12) and (13), we assume that the mixing time in a bath in the presence of the swirl motion can be approximated by

$$
\begin{aligned}
T_{\mathrm{m}}= & 4.92\left(D^{3} g / v_{\mathrm{L}}^{2}\right)^{7 / 32}\left(H_{\mathrm{L}} / D\right)^{4 / 3} Q_{\mathrm{g}}{ }^{-0.47} D^{1.97} H_{\mathrm{L}}{ }^{-1} v_{\mathrm{L}}^{0.47} \\
& \times\left(H_{\mathrm{in}} / H_{\mathrm{L}}\right)^{0.7-1.34 H_{\mathrm{L}} / D} \ldots \ldots \ldots \ldots \ldots \ldots \ldots \ldots \ldots \ldots \ldots \ldots \ldots \ldots \ldots \ldots \ldots \ldots \ldots \ldots \ldots \ldots \ldots \ldots \ldots \ldots \ldots \ldots \ldots \ldots \ldots
\end{aligned}
$$

In order to examine the applicability of Eq. (14), further experiments were carried out in a bath agitated by a J-shaped 


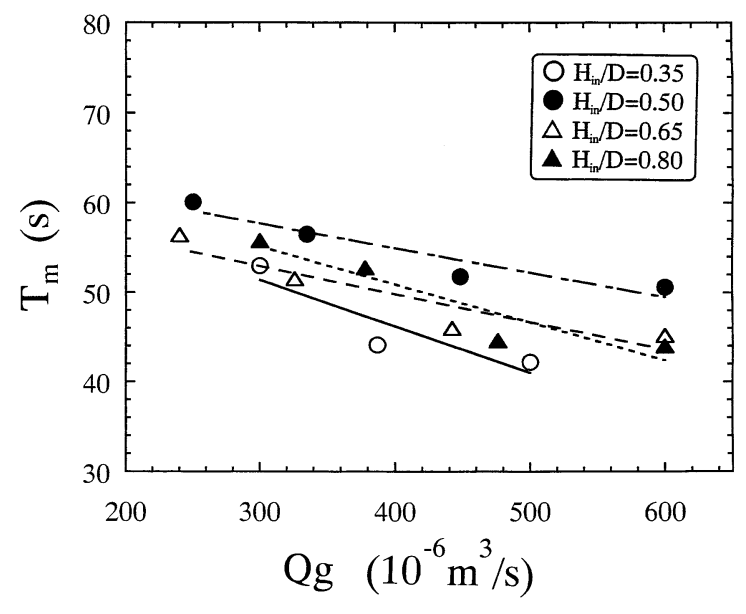

Fig. 9. Relationship between mixing time $T_{\mathrm{m}}$ and gas flow rate for $D=0.200 \mathrm{~m}$ and $H_{\mathrm{L}}=0.300 \mathrm{~m}$.

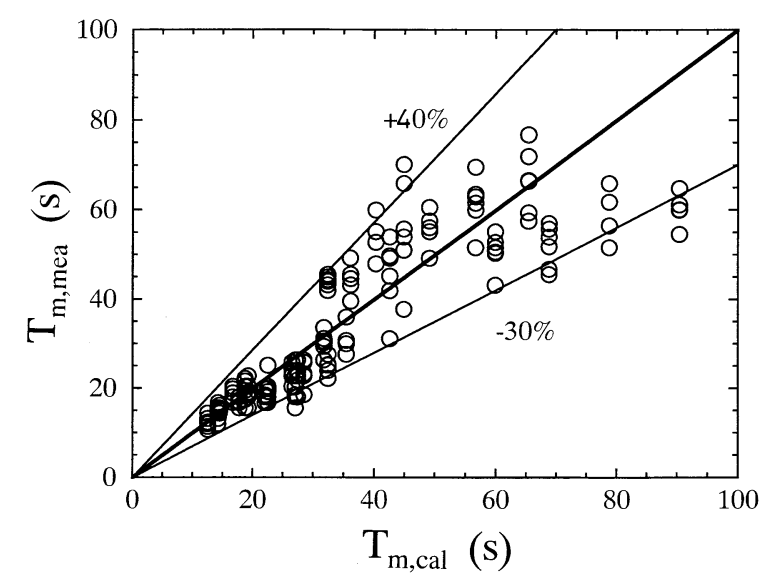

Fig. 10. Comparison of measured mixing time values with Eq. (14).

top lance in the presence of the swirl motion. Representative results for $D=0.200 \mathrm{~m}$ and $H_{\mathrm{L}}=0.300 \mathrm{~m}$ are shown in Fig. 9. Each line was drawn so as to best fit the measured values obtained under the same experimental condition. Mixing time measurements were also carried out for the remaining two vessels of $D=0.125 \mathrm{~m}$ and $0.400 \mathrm{~m}$. The measured values are compared with Eq. (14) in Fig. 10. All the measured values for the three vessels of different diameters can be approximated by this equation within a scatter of $-30 \%$ to $+40 \%$. Such a scattering level is acceptable in this kind of measurement. ${ }^{7,14)}$

\subsection{Applicability of Eq. (14) to Molten Metal Bath}

Empirical equations for mixing time derived for water baths agitated by bottom gas injection in the absence of swirl motions are known to be approximately applicable to molten steel baths. ${ }^{7)}$ Equation (14) would also be applicable to molten steel baths in the presence of the swirl motion of liquid provided that the applicable range of Eq. (14) is satisfied.

\section{Conclusion}

Mixing time, $T_{\mathrm{m}}$, of a water bath agitated by gas injection through a bottom nozzle or a J-shaped top lance was measured with an electrical conductivity sensor. The following empirical equation was proposed for $T_{\mathrm{m}}$ in the presence of swirl motion.

$$
\begin{aligned}
T_{\mathrm{m}}= & 4.92\left(D^{3} g / v_{\mathrm{L}}^{2}\right)^{7 / 32}\left(H_{\mathrm{L}} / D\right)^{4 / 3} Q_{\mathrm{g}}{ }^{-0.47} D^{1.97} H_{\mathrm{L}}{ }^{-1} v_{\mathrm{L}}^{0.47} \\
& \times\left(H_{\mathrm{in}} / H_{\mathrm{L}}\right)^{0.7-1.34 H_{\mathrm{L}} / D}
\end{aligned}
$$

All the $T_{\mathrm{m}}$ values obtained in this study could be correlated by this empirical equation within a scatter of $-30 \%$ to $+40 \%$.

\section{Nomenclature}

$a_{\mathrm{k}}, k: \quad$ coefficients $(-)$

$D$ : bath diameter (m)

$g$ : acceleration due to gravity $\left(\mathrm{m} / \mathrm{s}^{2}\right)$

$H_{\mathrm{L}}$ : bath depth (m)

$H_{\text {in }}$ : distance from nozzle tip to bath surface (m)

$L$ : length scale (m)

$Q_{\mathrm{g}}$ : gas flow rate $\left(\mathrm{m}^{3} / \mathrm{s}\right)$

Re: Reynolds number (-)

$T_{\mathrm{s}}:$ swirl period (s)

$T_{\mathrm{m}}$ : mixing time (s)

$T_{\mathrm{mB}}$ : mixing time for bottom gas injection (s)

$T_{\mathrm{mJ}}:$ mixing time for J-shaped top lance gas injection (s)

$v_{\mathrm{sp}}:$ superficial velocity $(\mathrm{m} / \mathrm{s})$

$v_{\mathrm{L}}$ : kinematic viscosity of liquid $\left(\mathrm{m}^{2} / \mathrm{s}\right)$

\section{REFERENCES}

1) M. Iguchi, S. Hosohara, T. Koga, R. Yamaguchi and Z. Morita: ISIJ Int., 33 (1993), No. 10, 1037.

2) M. Iguchi, S. Hosohara, T. Kondoh, Y. Itoh and Z. Morita: ISIJ Int., 34 (1994), No. 4, 330.

3) M. Iguchi, T. Kondoh, T. Uemura, F. Yamamoto and Z. Morita: Experiments in Fluids, 16 (1994), 255.

4) K. Sasaki, J. Yoshida, Y. Sasaki, T. Kumagai and M. Iguchi: Proc. 1st JSMF Annual Meeting, Jpn. Soc. Multiphase Flow, Osaka, (2000), 139.

5) K. Nakanishi, T. Fujii and J. Szekely: Ironmaking Steelmaking, 2 (1975), No. 3, 193.

6) ISIJ: 100th and 101th Nishiyama Memorial Seminar, Recent Developments in Steelmaking Technology using Gas Injection, ISIJ, Tokyo (1984).

7) D. Mazumdar and R. I. L Guthrie: ISIJ Int., 35 (1995), No. 1, 1.

8) S. Asai, T. Okamoto, J. C. He and I. Muchi: Trans. Iron Steel Inst. Jpn., 23 (1983), 43.

9) U. P. Shinha and R. J. McNallan: Metall. Trans. B, 16B (1985), 850.

10) T. Stapurewicz and N. J. Themelis: Can. Metall. Q., 26 (1987), No 2., 123.

11) J. Mietz and F. Oeters: Can. Metall. Q., 28 (1989), No. 1., 361.

12) D. Mazumdar, S. Das and S. Bajpayee: ISIJ Int., 37 (1997), No. 2 , 194.

13) M. Iguchi, K. Nakamura and R. Tsujino: Metall. Mater. Trans. B, 29 (1998), 569.

14) D. Mazumdar and R. I. L.Guthrie: ISS Trans., (1999), No. 4, 89.

15) M. Zhu, T. Inomoto, I. Sawada and T. Hsiao: ISIJ Int., 35 (1995), No. 5,472 .

16) M. Zhu, I. Sawada, N. Yamasai and T. Hsiao: ISIJ Int., 36 (1996), No. $5,503$.

17) H. Schlichting: Boundary Layer Theory, 7th ed., translated by J. Kestin, McGraw-Hill, New York, (1979), 90.

18) Y. Takatsuka, H. Kiuchi and M. Iguchi: CAMP-ISIJ, 13 (2000), 82. 